\title{
PROJETO TE VEJO NA ESCOLA: DESIGN AUDIOVISUAL PARA O ENSINO SOCIOAMBIENTAL INFANTIL
}

Joyce Carr

UNESP

carr.joyce@hotmail.com

Maria do Carmo Jampaulo Plácido Palhaci UNESP

palhaci@faac.unesp.br

Talitha Plácido Palhaci

UNESP

tah_palhaci@yahoo.com.br
Thiago Stefanin

UNESP

thiago_stefanin@hotmail.com

Édipo Ribeiro da Gama

UNESP

edipo_tails_milles@yahoo.com.br

Arissa Miki Takana Ito

UNESP

arissa_ito@hotmail.com

Resumo: O trabalho que se segue apresenta pesquisa-ação Thiollenti, 2002 em que se desenvolve o projeto de extensão universitária Te Vejo na Escola, criado em 2007, por alunos da Unesp, Campus de Bauru/SP visa contribuir como complementação a educação dentro e fora da escola. Tem como objetivo a produção de material didático audiovisual de apoio, com temática socioambiental (Unesco, 2007) para crianças de 6 a 9 anos de acordo com os Parâmetros Curriculares Nacionais, Brasil, 1997. As animações têm como personagem protagonista o Mico, um mico leão dourado que vive na Matinha que Resta. Este permite uma imersão no universo da criança para melhor receptividade da mesma, transformando o conteúdo acadêmico em uma narrativa com preocupação ambiental. O design, enquanto ferramenta, não só proporciona caráter lúdico ao ensino por meio da animação como também traduz codificando, Flusser, 2007, o conteúdo cientifico educacional em uma forma dinâmica para a compreensão infantil. Essa tradução se dá através da animação bidimensional e desenhos limpos e simples visualmente. A estrutura metodológica conta com entrevistas com profissionais acadêmicos das áreas determinada pelo tema do vídeo que assume uma responsabilidade com a informação, as etapas do processo criativo para produção das animações são organizadas segundo Selby, 2013, como elaboração de roteiros, storyboards, desenhos, animação $2 \mathrm{~d}$ e edição de som e imagem. Os resultados são 11 vídeos disponibilizados na internet no sitio Web TV Faac com acesso livre que colabora com a continuidade do ensino além da escola.

Palavras-chave: audiovisual, educação, infância, animação, socioambiental 